\title{
Individual differences in cognitive control on self-referenced and other-referenced memory
}

\section{Corrado Caudek ${ }^{1}$}

Department of Neurosciences, Psychology, Drug Research, and Child Health (NEUROFARBA), Università degli Studi di Firenze, Via di San Salvi, 12, Complesso di San Salvi, Padiglione 26, 50135 Firenze, FI, Italy

\section{A R T I C L E I N F O}

\section{Article history:}

Received 29 October 2013

Available online 6 October 2014

\section{Keywords:}

Self-reference effect

Memory

Self

Think-no-think

Negative cognitive style

Self-face

Emotion

\begin{abstract}
A B S T R A C T
Self-referenced information is better recalled than other-referenced information - a mnemonic advantage known as the "self-reference effect" (SRE). By using a modified version of the "think/no-think" (TNT) paradigm (Anderson \& Green, 2001), this study examined the effects of cognitive control on the SRE after the encoding stage. The results indicate that individual differences in personality traits and affective states strongly modulated the SRE after the TNT phase. For individuals high in negative cognitive style, an ironic enhancement of negative self-referenced memory produced a "maladaptive" SRE: better memory for negative self-referenced information than for negative other-referenced information, when trying to suppress that information. Before the TNT phase, instead, the SRE was characterized by the opposite bias. These results indicate that (1) the SRE is strongly affected by cognitive control after encoding, and (2) also in the non-clinical population, dysfunctional cognitive control can transform the SRE into a "maladaptive" memory bias.
\end{abstract}

(c) 2014 Elsevier Inc. All rights reserved.

\section{Introduction}

Self-relevant information is better remembered compared to information related to another person, a phenomenon known as the "self-reference effect" (SRE). The SRE is a pervasive memory phenomenon that occurs when individuals are instructed to evaluate trait words in relation to self or to others (e.g., Klein \& Kihlstrom, 1986; Rogers, Kuiper, \& Kirker, 1977; Symons \& Johnson, 1997), for objects that had been associated with the self or with other people (Cunningham, Turk, Macdonald, \& Macrae, 2008), in mild depressive and healthy individuals (Kuiper \& Derry, 1982), and across age groups (Gutchess, Kensinger, Yoon, \& Schacter, 2007).

Typically, the processing of self-related information involves the processing of emotional valence (Glisky and Marquine, 2009). If individuals remember better positive self-referenced information than positive other-referenced information, then the SRE has an "adaptive" role, because it can maintain or increase the positivity of one's self-concept (Leary, 2007). On the other hand, a tendency for negative self-referenced information to be remembered better than negative other-referenced information is "maladaptive," because it may result in a distorted mental representation of the social environment and it may contribute to negative self-appraisal and low self-concept (e.g., Caudek \& Monni, 2013).

The purpose of the present study is to examine individual differences in the memory of valenced self-referenced information and to determine the extent to which they are mediated by memory control. It is here hypothesized that individuals

E-mail address: corrado.caudek@unifi.it

1 I wish to thank Giorgio Gronchi and Tessa Marzi for helpful discussions, and Eleonora Belli, Filippo Cicali, Giulia Gerlotti, and Irene Mangini for their help in developing the stimuli and collecting data. 
with a dysfunctional cognitive processing style, due to maladaptive control over self-related information, reverse the bias towards positive information which characterizes the SRE in healthy individuals (e.g., D'Argembeau, Comblain, \& Van der Linden, 2005; Watson, Dritschel, Obonsawin, \& Jentzsch, 2007). Cognitive control after encoding might thus contribute to maintain a positivity bias for self-related memories in some individuals, while creating a bias which favors negative selfrelated information, in others.

\subsection{Self-reference effect and memory biases for valent information}

In the non-clinical population, positive information tends to be remembered better than negative information, but only when it is related to the self. For example, D'Argembeau et al. (2005) asked participants to recall trait adjectives that had been previously processed either in reference to the self or in reference to a stranger. They found better recall performance for positive than for negative trait adjectives, but only when the adjectives were encoded with reference to the self (see also Kuiper \& Derry, 1982; Sedikides \& Green, 2000, 2004). It has also been shown that the affective intensity associated with autobiographical memories decreases more rapidly with time for negative memories than for positive memories (Walker \& Skowronski, 2009), and that self-related memories are distorted by the tendencies to form positive (Wilson \& Ross, 2003) and consistent (Conway, 2005; Conway, Singer, \& Tagini, 2004) memories about ourselves.

Also in healthy subjects, however, the positivity bias that characterizes the SRE can sometimes be replaced by an opposite bias. For example, Caudek and Monni (2013) found that the self-face advantage (i.e., better memory recognition for the selfface than for stranger's faces) can be modulated by individual differences in negative cognitive style, defined as the tendency to attribute negative life events to stable, global, and internal causes (Alloy et al., 2000; Alloy, Abramson, Keyser, Gerstein, \& Sylvia, 2008). In the study of Caudek and Monni, participants high in negative cognitive style who, during the experiment, experienced higher levels of sadness, displayed a stronger self-face advantage for sad expressions than for happy expressions. The remaining participants displayed an opposite bias (a stronger self-face advantage for happy expressions than sad expressions), or no bias. These results thus suggest that, also in a healthy sample, the SRE might be biased towards positive or towards negative information, depending on individual differences in cognitive style.

\subsection{Individual differences in cognitive control over self-referenced memory}

The SRE is usually attributed to the specific attentional processing for information related to the self, relative to processing of information about other people. According to the standard account of the SRE, information related to the self compared to other people is encoded more fully and it gives rise to the formation of richer, more organized, and more elaborated memory representations (Klein, 2012; Klein \& Kihlstrom, 1986; Klein \& Loftus, 1988; Symons \& Johnson, 1997). Even though there is strong evidence of the importance of the encoding stage for the SRE, little is know about how the SRE is modulated by the memory processes that take place after encoding. The main purpose of the present study is to investigate the individual differences in the effects on the SRE of cognitive control over memory after the encoding stage.

Diathesis-stress models postulate that cognitively vulnerable individuals (e.g., depressed and dysphoric individuals, but also individuals at risk for, but without a history of, depression) harbor dysfunctional information-processing schemas that influence how stimuli are selected, encoded, interpreted, and retrieved (Clark \& Beck, 2010; Disner, Beevers, Haigh, \& Beck, 2011). Becks cognitive theory (Beck, 1967) suggests that dysfunctional information-processing schemas remains dormant until activated by internal or external stressors. Indeed, empirical research has provided strong evidence that cognitively vulnerable individuals have reduced ability to regulate and control negative information in memory, especially self-related information, which gives rise to explicit memory biases (Alloy et al., 2000).

It is here hypothesized that individuals with a negative cognitive style (Alloy et al., 2000; Safford, Alloy, Abramson, \& Crossfield, 2007), and/or individuals who show a tendency toward rumination (Dieler, Herrmann, \& Fallgatter, 2013), will be more likely to manifest a maladaptive SRE compared to individuals not having these personality traits, as a consequence of their dysfunctional attempts to control the process of memory retrieval. In order to activate latent cognitive vulnerability, in the present study participants were primed with a negative mood induction (Segal \& Ingram, 1994).

\section{Experiment}

A modified version of the think/no-think procedure was used to study the individual differences in the effects of cognitive control over memory of information that is relevant to the self, as opposed to memory of information that pertains to other people. In the first phase of the experiment, participants were asked to learn the associations between a set of pictures portraying each participant and a set of strongly (positively or negatively) emotionally valenced images. For comparison purposes, pictures portraying a stranger were also used as cues for the learned associations. A cued-recognition test was administered before and after the think/no-think phase.

The main questions were as follows (1) Is the SRE characterized by a positivity bias before the think/no-think phase? (2) Is the SRE affected by cognitive control after encoding? (3) Do individual differences in personality traits and affective states modulate the effects of cognitive control on the SRE? Control observations were also gathered in order to determine whether maladaptive self-focus is mainly influenced by personality traits or whether it arises from a generic impairment involving executive functions (e.g., Levy \& Anderson, 2008). 


\subsection{Method}

\subsubsection{Participants}

A total of 65 experimentally naïve undergraduate students from Florence University participated in the study (age 20-34, 32 female), all with normal or corrected-to-normal vision. All gave written informed consent and the study was approved by the Departmental Ethics Committee, Dipartimento di Psicologia, Università degli Studi di Firenze, Italy.

\subsubsection{Apparatus}

Stimuli were presented and responses collected using a custom script written with the PsychToolbox extension (Brainard, 1997; Pelli, 1997) of MATLAB (Mathworks, Massachusetts) on a Mac Pro computer connected to a 17-in. video monitor viewed at a distance of $70 \mathrm{~cm}$.

\subsubsection{Stimuli}

Forty photographs (cue images) were taken of each participant under normal lighting, with different body postures, different objects, or with different garments (Fig. 1). Eighty target pictures were selected from the International Affective Picture System (IAPS; Lang, Bradley, \& Cuthbert, 2005) stimulus set. For each of the two identities represented in the cue images, half of the target pictures had a negative valence and half had a positive valence. Mean valence (positive: 7.20, S.E. $=0.11$; negative: 3.01 , S.E. $=0.11)$ differed significantly between the positive and negative pictures $\left(t_{77.9}=27.13\right.$, $p=.001$, Welch correction), while arousal values were kept similar for the two stimulus sets (positive: 4.58 , S.E. $=0.15$; negative: 4.83 , S.E. $=0.11 ; t_{72.8}=1.31, p=.192$, Welch correction) .

\subsubsection{Psychometric tests and other materials}

The Cognitive Style Questionnaire - Short Form (CSQ-SF; Meins et al., 2012) is a 8-item self-report measure of cognitive and behavioral coping strategies. Participants rate the probable consequences of 8 hypothetical negative events and the implications of each event for the self-concept. The CSQ had been translated to and validated in Italian in earlier research (Caudek \& Monni, 2013; Ceccarini \& Caudek, 2013; Sica, Caudek, Rocco Chiri, Ghisi, \& Marchetti, 2012).

The Dysfunctional Attitudes Scale (DAS; Weissman \& Beck, 1978) is a 40-item self-report inventory of maladaptive attitudes that are thought to confer vulnerability for depression. The italian version of the DAS-A was used (Di Maria \& Di Nuovo, 1991).

The Ruminative Response Scale (RRS; Nolen-Hoeksema \& Morrow, 1993) of the Response Styles Questionnaire includes 22 items describing the tendency to ruminate in response to depressed mood. The RRS assesses responses to dysphoric mood that are focused on the self, on symptoms, or on possible consequences and causes of moods. The Italian version of the RRS was used (Palmieri, Gapsarre, \& Lanciano, 2007).

The Center for Epidemiologic Studies Depression Scale (CES-D; Radloff, 1991a, 1991b) is a 20-item self-report inventory sensitive to individual differences in depressive severity in the student population (Olino et al., 2012). The Italian version of the CES-D was used (Fava, 1982).

The Cognitive Reflection Test (CRT; Frederick, 2005) is used to differentiate between more impulsive and more reflective decision-making. The test consists of three items for which the intuitive response is incorrect. Performance on the CRT is related to inhibitory control in executive functioning: Respondents not having sufficient inhibitory control to override their impulsive responses tend to produce incorrect answers (Aron, 2008).

The Visual Analogue Scale (VAS; McCormack, Horne, \& Sheather, 1988) is a self-report device used to measure respondents' perceptions of their own mood (e.g., Scherrer \& Dobson, 2009). Participants rate their mood by placing a vertical mark on a $100-\mathrm{mm}$ line, marked with "Not at all sad" on the left end and "Extremely sad" on the right. A score from 0 to 100 is derived by measuring the distance of the mark from the left pole.

\subsubsection{Procedure}

The procedure comprised the following phases (Fig. 2).

Preliminary session. During an initial session that took place the same day as the experiment, participants completed a battery of three self-report scales: CSQ DAS, CES-D, and RRS (Table 1). A number of pictures of each participants was also taken (Fig. 1). These pictures were then used as the "cue" stimuli in the think/no-think phase of the experiment.

Mood induction procedure (MIP). Prior to the mood induction, participants rated their baseline mood with the VAS, for which they were instructed to focus on how they were feeling at that moment. They were then asked to get into a negative mood state using the music, the suggested imagery, and the movie, and to stay in that state until the whole session was completed (Robinson, Grillon, \& Sahakian, 2012). Participants were instructed to listen to Albinoni's "Adagio" in G Minor while on the screen was presented a random selection of emotionally charged sentences (Velten, 1968). Immediately after this phase, which lasted $7.5 \mathrm{~min}$, participants were instructed to watch a video clip in order to increase their emotional engagement and to maintain their sad mood (Jallais \& Gilet, 2010). The video was a 3-min scene of a boy crying over his father's death from the movie "The Champ" (Lovell \& Zeffirelli, 1979). Previous studies have tested the reliability of this clip to elicit sadness (Hewig et al., 2005). Each participant was alone while undergoing the mood induction. Following the induction, the mood check was administered again. 


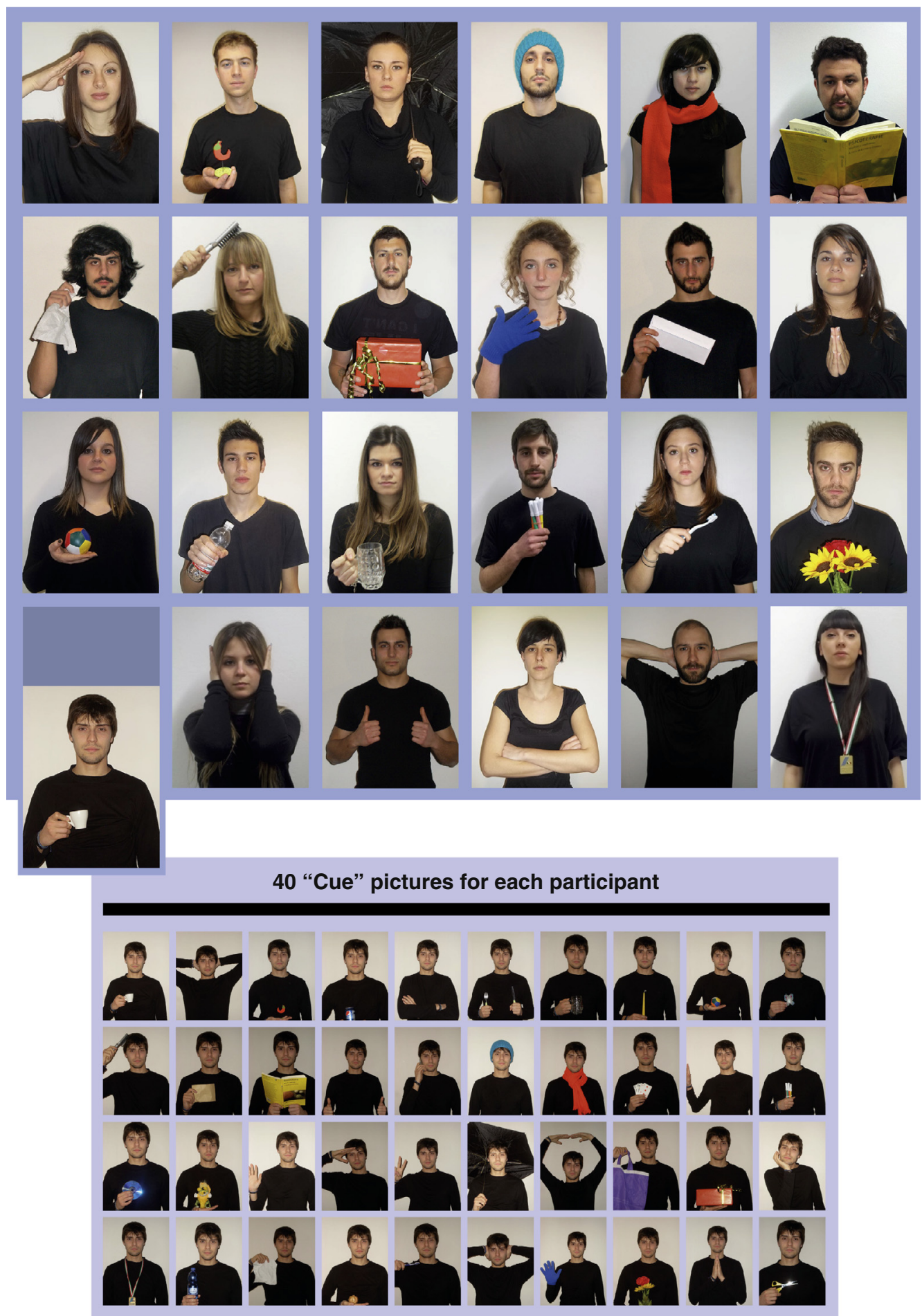

Fig. 1. Examples of "cue" pictures. 40 cue pictures depicted the participant running the experiment and 40 depicted a stranger. 


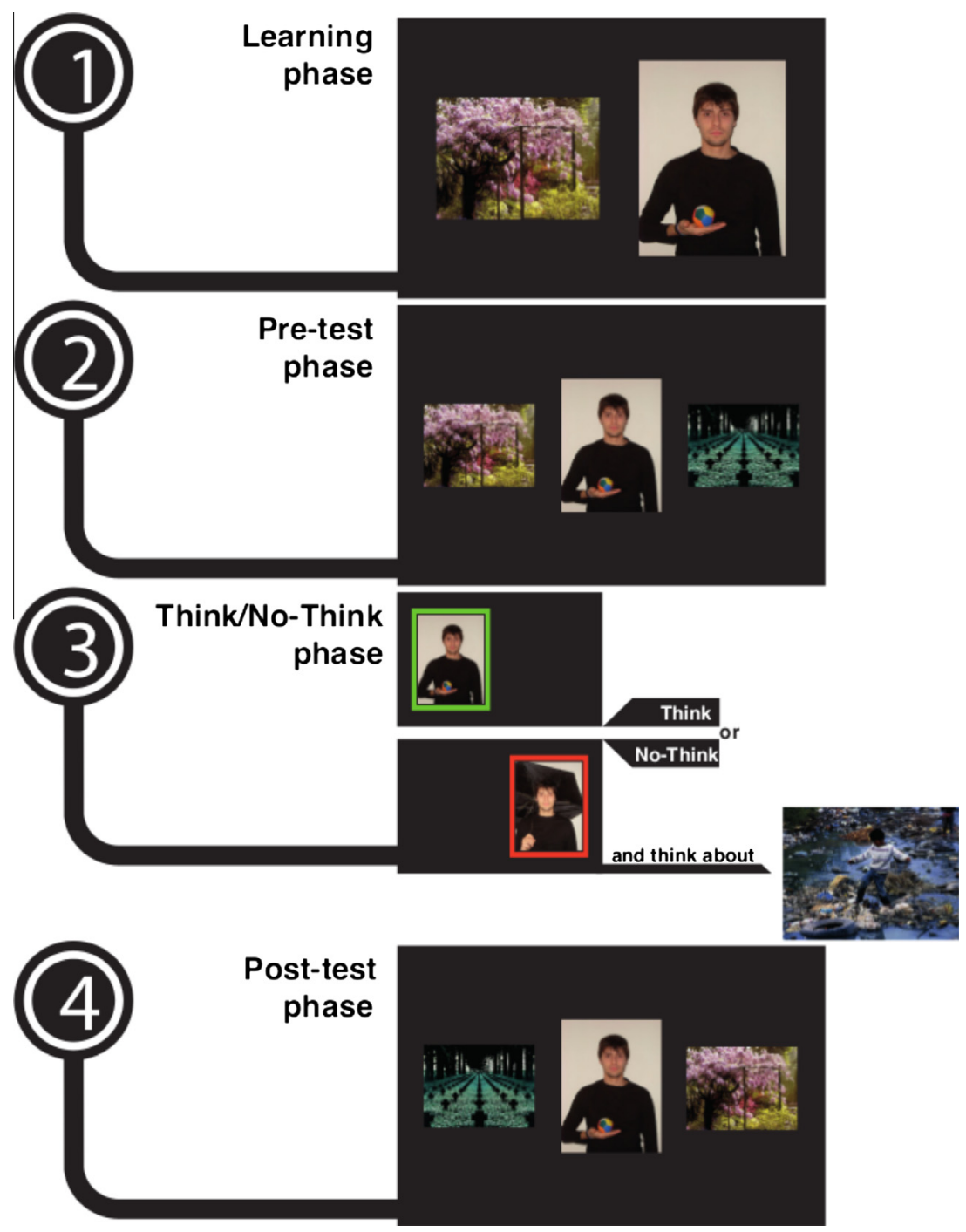

Fig. 2. Experimental procedure. (1) Participants were first trained to associate 40 cue-target pairs. $(2,4)$ On each trial of the pre-test and of the post-test, each cue was shown again and participants were asked to recognize the previously associated target picture, which was presented together with a foil. (3) During the think/no-think phase, participants viewed only the cues. On some trials they were instructed to recall the previously learned target pictures; on other trials they were instructed not to let the previously associated targets enter consciousness and, instead, to recall the substitute.

Table 1

Participant characteristics: mean, standard deviation, and range. CSQ is Cognitive Style Questionnaire. DAS is Dysfunctional Attitude Scale. CES-D is Center for Epidemiologic Studies Depression Scale. RRS is Ruminative Response Scale. RRS-R, RRS-B, and RRS-D are the Reflection, Brooding, and Depression subscales of the RRS, respectively.

\begin{tabular}{ll}
\hline Age & $24.9(2.33)[20,34]$ \\
\hline Gender ratio (F/M) & $32 / 33$ \\
CSQ & $179(25.9)[124,241]$ \\
DAS & $122(23.4)[77,193]$ \\
CES-D & $12.3(7.1)[1.0,39.0]$ \\
RRS & $46.7(10.3)[29.0,86.0]$ \\
RRS-R & $10.6(2.8)[6.0,19.0]$ \\
RRS-B & $10.9(3.1)[6.0,20.0]$ \\
RRS-D & $25.1(6.2)[15.0,47.0]$ \\
\hline
\end{tabular}


Learning phase. Participants were trained to associate 80 cue-target pairs which were presented sequentially. The presentation order was randomly determined for each participant. Participants were instructed to try to remember each cue-target association for a later test. In 40 cases, the cue was a picture of the participant whereas in the remaining cases the cue was a picture of a stranger. Each cue-target pair was presented side-by-side on the screen for $2 \mathrm{~s}$. The relative left/right position of the two pictures was chosen at random for each trial and each participant. After completion of the learning phase, the mood check was administered again.

Pre-test. For each participant, the pre-test comprised 80 cued recognition trials. In each trial, one of the 80 cues used in the learning phase was shown in the center of the screen together with the target image that, in the learning phase, was associated with the presentation of the cue and with a foil (one on the left side of the cue, the other on the right). The foil was a target image that, in the learning phase, was associated with the presentation of a different cue, with the constraint that each target image could serve as foil only once in 80 trials. The relative left/right position of the target/foil pair was chosen at random for each trial and each participant. The order of presentation of the sequence of the cue images was chosen at random for each participant and differed from the presentation order in the learning phase. On each trial, participants were required to indicate via keypress which of the two images shown on the left and on the right of the cue was the target. The mood check was administered again after completion of the pre-test.

Presentation of a substitute image. A negative image selected from the IAPS stimulus set, but not used either as target or as foil in the pre-test and post-test, was chosen as the substitute for "no-think" trials (valence: 3.8; arousal: 4.5). Participants were instructed to memorize this picture, so that they could use it to help them suppress targets in the "no-think" trials of the experiment (see Hertel \& Calcaterra, 2005; Joormann, Hertel, LeMoult, \& Gotlib, 2009).

Think/no-think phase. Each trial started with showing the participants a black screen with the instructions. After the keypress, one of the 80 cue images was shown in the center of the screen for $1.5 \mathrm{~s}$, surrounded by either a green or a red frame. When the frame was green, participants were instructed to try to recall the target. They were told that they could use all the time that they needed, also after the cue image disappeared from the screen. When the frame was red, in addition to the suppression instructions used by Anderson and Green (2001), participants were instructed to recall and to create a vivid image of the substitute. The experimenter strongly emphasized the importance of never thinking about the target during "no-think" trials. It should be noted that use of a substitute in the present adaptation of the think/no-think paradigm departs from the original task of Anderson and colleagues and the modified task could involve different processes: The "no-think" trials involve the creation of a new link between the cue and the substitute rather than simply the control of memory retrieval.

After each "no-think" trial, participants judged via keypress whether they were able not to think about the target and to recall the substitute. These judgments assessing the compliance with the suppression instructions were used as an alternative to the Strategy Questionnaire of Hertel and Calcaterra (2005) and Joormann, Hertel, Brozovich, and Gotlib (2005). After each "think" trial, participants gave a retrospective confidence judgment (RCJ), which asked them to estimate whether they had been or had not been able to recall the target.

The think/no-think phase was repeated four times. Afterwards, the mood check was administered again. ${ }^{2}$

Post-test. The post-test was identical to the pre-test. The order of presentation of the trials was random for each participant and different from the pre-test. The relative left/right positions of target and foil were also determined at random on each trial and for each participant. ${ }^{3}$

Debriefing phase. Following the completion of the experiment, participants were asked to return to their normal frame of mind and they were thoroughly debriefed concerning the purpose of research. Those participants who showed a continued response to the sad mood manipulation were cheered up by the experimenter to neutralize any increase in depression due to the sad mood induction procedure. Participants were encouraged to contact the experimenter in case they were experiencing any long-lasting sad mood. Each participant was contacted by phone after one week and three weeks. None of the participants reported any problem caused by the experimental procedure.

\subsection{Statistical analyses}

Generalized estimating equation (GEE) regression models with logit link assuming exchangeable correlation were used to account for multiple data points from the same participants and the resulting stochastic non-independence of observations. The "recognition correctness" (correct/incorrect) was the dependent variable and the within-subjects independent variables were think (whether the cue image was used in a "think" or "no-think" trial), referent (whether the cue image portrayed the participant or a stranger), and valence (whether the valence of the target image was positive or negative). To control for the pre-test accuracy, the post-test responses were analyzed separately, depending on whether the cue-test associations were evaluated correctly or not on the pre-test.

\footnotetext{
${ }^{2}$ Differently than in the original think/no-think procedure, no baseline condition was used. However, this is not a limit of present design because the purpose was to study the effect of cognitive control on self-referential memory, not to measure the suppression effect in the think/no-think task (see also Raaijmakers \& Jakab, 2012).

3 Although the majority of think/no-think research has used recall as the dependent measure, in some cases a recognition test has also been employed (Hart \& Schooler, 2012; Tomlinson, Huber, Rieth, \& Davelaar, 2009). In the present study, cued recognition was preferred over cued recall because it provides a better protection toward the possible effects of the demand characteristics of the think/no-think procedure (e.g., Hart \& Schooler, 2012; Noreen \& MacLeod, 2013).
} 
A correct pre-test response signals a high strength of encoding. In these circumstances, the probability of responding correctly on the post-test is expected to be high. Instead, an incorrect pre-test response signals a weak encoding. For these cuetarget associations, the probability of responding correctly on the post-test is .5 if participants resort to guessing, being unable to retrieve the target associated with the retrieval cue. If the probability of responding correctly on the post-test is different from .5, this means that some form of encoding did take place also for those cue-target associations that had been judged incorrectly on the pre-test. A probability smaller than .5 indicates that suppression took place, because on the posttest participants prefer the foil to the target; a probability higher than .5 indicates that the retrieval of the target is better on the post-test than on the pre-test (i.e., it indicates that the think/no-think phase has strengthened the memory trace).

\subsection{Results}

\subsubsection{Principal components analysis}

A principal component analysis (PCA) was applied to the results from the 65 participants on the CSQ DAS, CES-D questionnaires, together with the results from three subscales of the RRS questionnaire (Reflection, Brooding, and Depression) in order to reduce the dimensionality of the personality measures and of the dysphoria level for further analyses (Kanai \& Rees, 2011). A parallel analysis indicated the presence of a single eigenvalue higher than one (i.e., 2.06). There were only two salient loadings on the first principal component, .786 for the CSQ scores and .606 for the DAS scores, indicating that, in the present sample the inter-individual differences in personality traits and level of affect depend, for the most part, on differences in negative cognitive style. In the following analyses, therefore, the first PC (denoted as Vulnerability Factor, VF) was the primary measure aimed at accounting for the individual differences in the effects of cognitive control on the SRE. ${ }^{4}$

\subsubsection{Effect of sad mood induction}

VAS ratings pre-MIP were analyzed by multiple regression with VF, CES-D, and RRS as predictors. The VAS ratings preMIP were positively associated to the CES-D scores, $t_{61}=5.05, p=.001$, confirming the validity of the VAS as a measure of negative mood. The variables $\mathrm{VF}$ and RRS were not significantly associated with pre-MIP VAS, $F_{2,61}=0.25, p=.78$.

The mood induction produced significant changes in VAS self-rated sadness. Post-induction sadness was significantly lower than pre-induction sadness: Mean change in mood was $37.1 \mathrm{~mm}, S . E .=3.5, t_{64}=10.7, p=.001$.

The VAS test was administered six times throughout the experiment. The effect of the negative mood induction decreased significantly with time, $F_{1,61.4}=57.66, p=.001$, but this decrease was not affect by the level of negative cognitive style (VF), $F_{1,62.3}=1.28, p=.26$. The final post-MIP VAS scores were significantly higher than the pre-MIP VAS scores: Mean change in mood was $6.2 \mathrm{~mm}$, S.E. $=2.6, t_{64}=2.35, p=.022$.

\subsubsection{Pre-test $S R E$}

On the pre-test, the probability of a correct recognition was equal to .80 when the cue portrayed the participant and .75 when the cue portrayed a stranger. A generalized estimating equation (GEE) analysis showed that this difference was statistically significant, $\chi_{1}^{2}=9.04, p=.0026$. For negative targets, instead, no SRE was found: The probability of a correct recognition was equal to .77 when the cue portrayed the participant or a stranger. Pre-test accuracy was not modulated by individual differences in negative cognitive style, $\chi_{4}^{2}=0.95, p=.92$, dysphoria, $\chi_{4}^{2}=8.18, p=.085$, or rumination, $\chi_{4}^{2}=8.7$, $p=.069$.

\subsubsection{Post-test SRE}

For those target-cue associations that had been judged correctly on the pre-test, a GEE analysis indicated that, after the think/no-think phase, an SRE was present for positively valenced targets (the proportions of correct responses were 1.0 and .81 for self-referenced associations and other-referenced associations, respectively), $\chi_{1}^{2}=201, p=.001$, but not for negatively valenced targets (the proportion of correct responses was equal to .83 for both self-referenced and other-referenced associations), $\chi_{1}^{2}=0.03, p=.86$.

For those target-cue associations that had been judged incorrectly on the pre-test, post-test performance was not affected by the variables referent and valence, $\chi_{3}^{2}=3.86, p=.28$. The proportion of correct responses was equal to .47 .

\subsubsection{Post-test SRE: individual differences in negative cognitive style}

Four separate GEE models were run to test the hypothesis that the "adaptive" SRE found on the pre-test can turn into a "maladaptive" SRE on the post-test as a consequence of dysfunctional cognitive control. The complete dataset was divided into four subsets, depending on the valence of the target images and the correctness of the pre-test response. In each analysis, the dependent variable was the post-test accuracy $\left(Y_{\text {post }}\right)$, and the independent variables were think and referent, together with the summary measure VF derived from the PCA of the psychometric data. The statistical model was thus equal to

$$
\operatorname{logit}\left(Y_{\text {post }}\right)=\alpha+\beta_{1} \mathrm{VF}+\beta_{2} \mathrm{~T}+\beta_{3} \mathrm{R}+\beta_{4} \mathrm{VF} \cdot \mathrm{T}+\beta_{5} \mathrm{VF} \cdot \mathrm{R}+\beta_{6} \mathrm{~T} \cdot \mathrm{R}+\beta_{7} \mathrm{VF} \cdot \mathrm{T} \cdot \mathrm{R}
$$

\footnotetext{
${ }^{4}$ To ease interpretation of coefficients, VF was centered (mean $=0$ ) and scaled in the $[-0.5,0.5]$ interval so that the range of variation was 1 .
} 


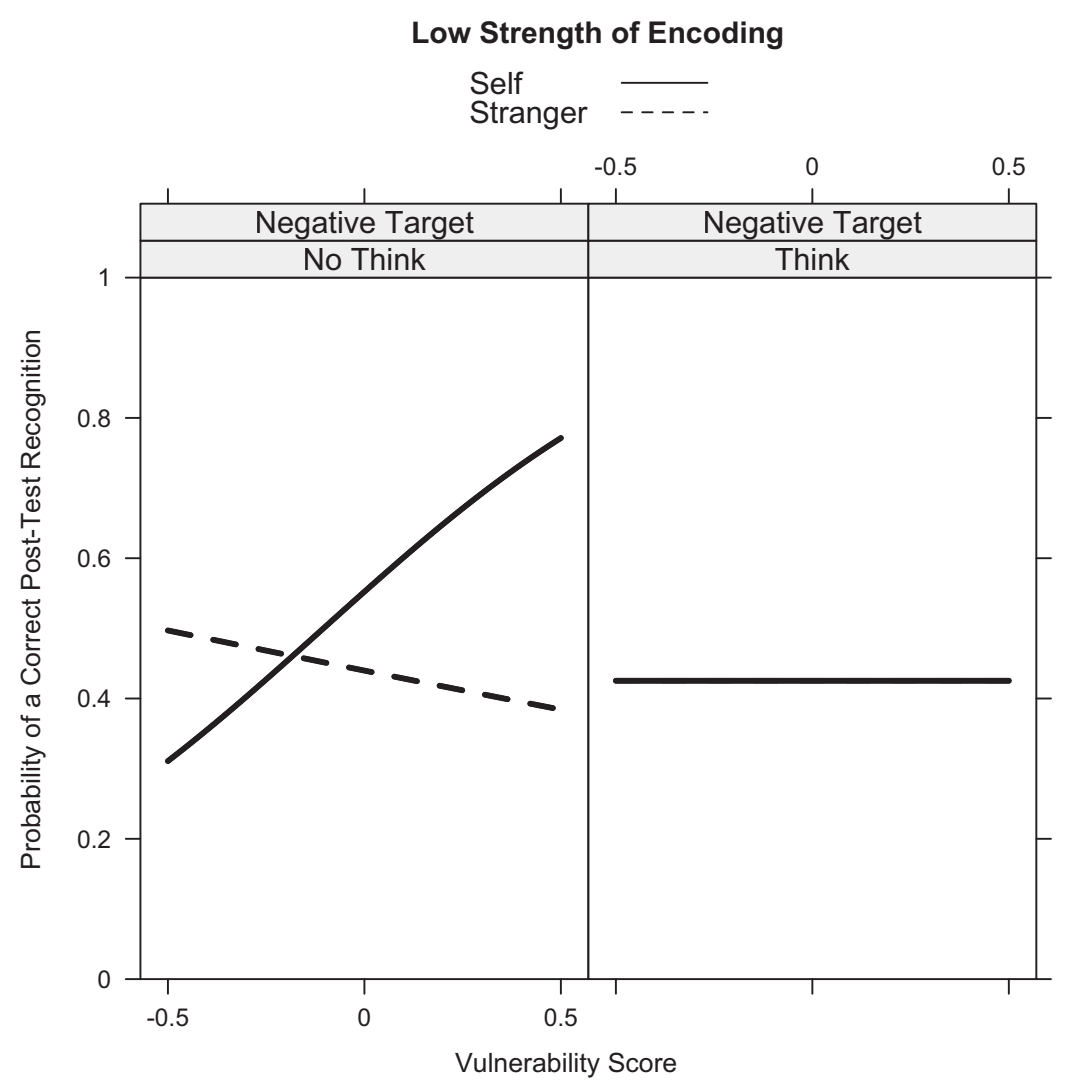

Fig. 3. Post-test accuracy for incorrect pre-test responses, negative targets. Probabilities of correct recognition as a function of vulnerability score, think, valence, and referent. Only the significant effects are shown.

with $\mathrm{VF}=$ Vulnerability Factor, $\mathrm{T}=$ think ("think" or "no-think" trial), and $\mathrm{R}=$ referent (the cue was a picture of the participant or a picture of a stranger). ${ }^{5}$

Incorrect pre-test responses, negatively valenced target pictures. The 3-way interaction was statistically significant, $\chi_{1}^{2}=8.09$, $p=.004$. For "no-think" trials, the $\mathrm{VF} \times$ referent interaction was statistically significant, $\chi_{1}^{2}=8.06, p=.004$. VF affected post-test accuracy when the cue image portrayed the participant, $\chi_{1}^{2}=5.66, p=.017$, but not when the cue image portrayed a stranger, $\chi_{1}^{2}=0.33, p=.567$. The predicted probabilities are shown in Fig. 3. For "think" trials, instead, post-test accuracy was not affected by VF or referent, $\chi_{3}^{2}=1.9, p=.59$. The proportion of correct responses was .42 .

For each participant, the proportions of correct post-test responses for self-referenced and other-referenced associations were also compared, Kendall $\tau_{b}=0.274$ (95\% CI: 0.07, 0.48). In the group of participants who scored below the 25th percentile on the VF scale, 3 participants showed the SRE, 5 showed the opposite effects, with 3 ties; in the group of participants who scored between the 25th percentile and 75th percentile, 10 showed the SRE, 9 showed the opposite effect, with 3 ties; in the group of participants who scored above the 75th percentile, 7 participants showed the SRE, none showed the opposite effect, with 5 ties.

Incorrect pre-test responses, positively valenced target pictures. The average proportion of correct post-test responses was equal to .49. None of the variables in the model nor any of their interactions attained statistical significance, $\chi_{7}^{2}=4.2, p=.76$.

Correct pre-test responses, negatively valenced target pictures. The average proportion of correct post-test responses was equal to .83. None of the variables in the model nor any of their interactions was statistical significant, $\chi_{7}^{2}=5.68, p=.58$.

Correct pre-test responses, positively valenced target pictures. Post-test accuracy was affected by both referent, $\chi_{1}^{2}=6.67$, $p=.01$, and think, $\chi_{1}^{2}=5.41, p=.020$, as indicated in Fig. 4. None of the other variables or interactions attained statistical significance, $\chi_{5}^{2}=4.44, p=.49$. Without considering the size of the effect, but only its direction, 29 participants showed the SRE, 26 showed the opposite effect, with 5 ties.

\footnotetext{
${ }^{5}$ Separate GEE models were run for target-cue associations that had been responded to correctly or incorrectly on the pre-test because cognitive control might affect the SRE differently, depending on "strength of encoding" [for the present purposes, strength of encoding (high or low) was indexed by pre-test accuracy (correct or incorrect response)]. Separate analyses for target-cue associations to which participants had provided a correct or an incorrect pre-test response also had the benefit to provide statistical control over pre-test recognition accuracy.
} 


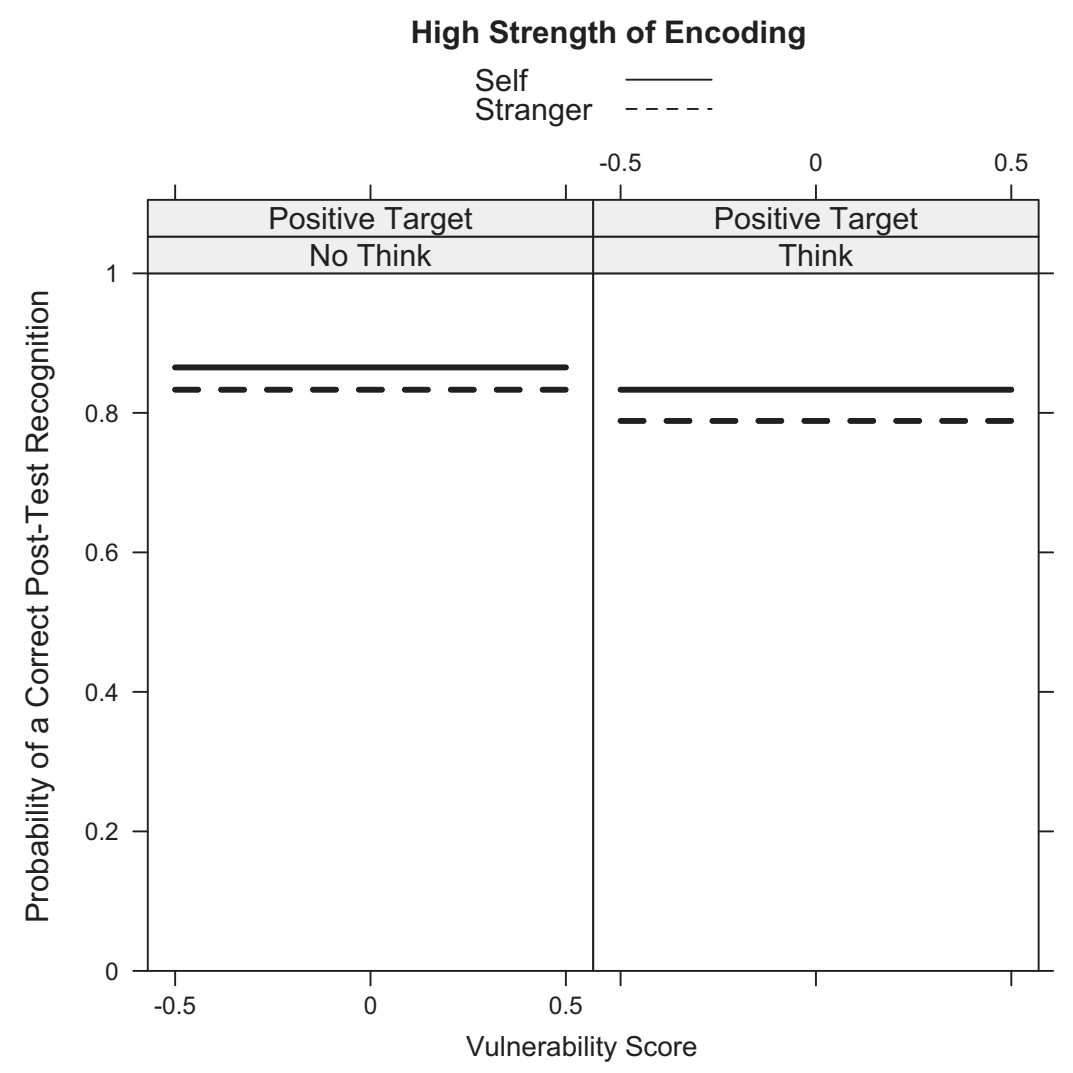

Fig. 4. Post-test accuracy for correct pre-test responses, positive targets. Probabilities of correct recognition as a function of vulnerability score, think, valence, and referent.

\subsubsection{Post-test SRE: individual differences in rumination}

The analyses described in Section 2.3.5 were repeated by using the RRS scores in place of VF.

Incorrect pre-test responses. Individual differences in rumination, as measured by the RRS scores, were not a significant predictor of post-test accuracy and they did not interact with either think or referent (negatively valenced targets: $\chi_{4}^{2}=0.88, p=.93$; positively valenced targets: $\chi_{4}^{2}=1.42, p=.84$ ).

Correct pre-test responses, negatively valenced target pictures. The RRS scores did not significantly affect post-test accuracy, nor they interacted with think or referent, $\chi_{4}^{2}=3.4, p=.49$.

Correct pre-test responses, positively valenced target pictures. In "think" trials, RRS had a statistically significant effect on post-test accuracy when the cue images portrayed a stranger, $\chi_{1}^{2}=5.43, p=.02$ (the predicted probability of a correct post-test response decreased from .85 to .62 in the range of the RRS scores of the present sample), but not when the cue images portrayed the participant, $\chi_{1}^{2}=0.95, p=.33$ (Fig. 5). In "no-think" trials, conversely, the RRS scores did not affect post-test accuracy, nor they interacted with referent, $\chi_{2}^{2}=0.60, p=.74$.

For each participant, the proportions of correct post-test responses for self-referenced and other-referenced associations were also compared, Kendall $\tau_{b}=0.235$ (95\% CI: 0.01, 0.46). In the group of participants who scored below the 25th percentile on the RRS scale, 7 participants showed the SRE, 8 showed the opposite effects, with 1 tie; in the group of participants who scored between the 25th percentile and 75th percentile, 18 showed the SRE, 9 showed the opposite effect, with 8 ties; in the group of participants who scored above the 75th percentile, 10 participants showed the SRE and 4 showed the opposite effect.

\subsubsection{Post-test SRE: individual differences in dysphoria}

The analyses described in Section 2.3.5 were repeated by using the CES-D scores in place of VF.

Incorrect pre-test responses, negatively valenced target pictures. The $\mathrm{CES}-\mathrm{D}$ scores were not a significant predictor of posttest accuracy and they did not interact significantly with either think or referent, $\chi_{4}^{2}=6.83, p=.15$.

Incorrect pre-test responses, positively valenced target pictures. For "no-think" trials, the CES-D $\times$ referent interaction was statistically significant, $\chi_{1}^{2}=5.03, p=.025$ (see Fig. 6). For "think" trials, instead, neither the CES-D scores, nor the CES$\mathrm{D} \times$ think interaction affected post-test accuracy, $\chi_{2}^{2}=1.6, p=.45$. 


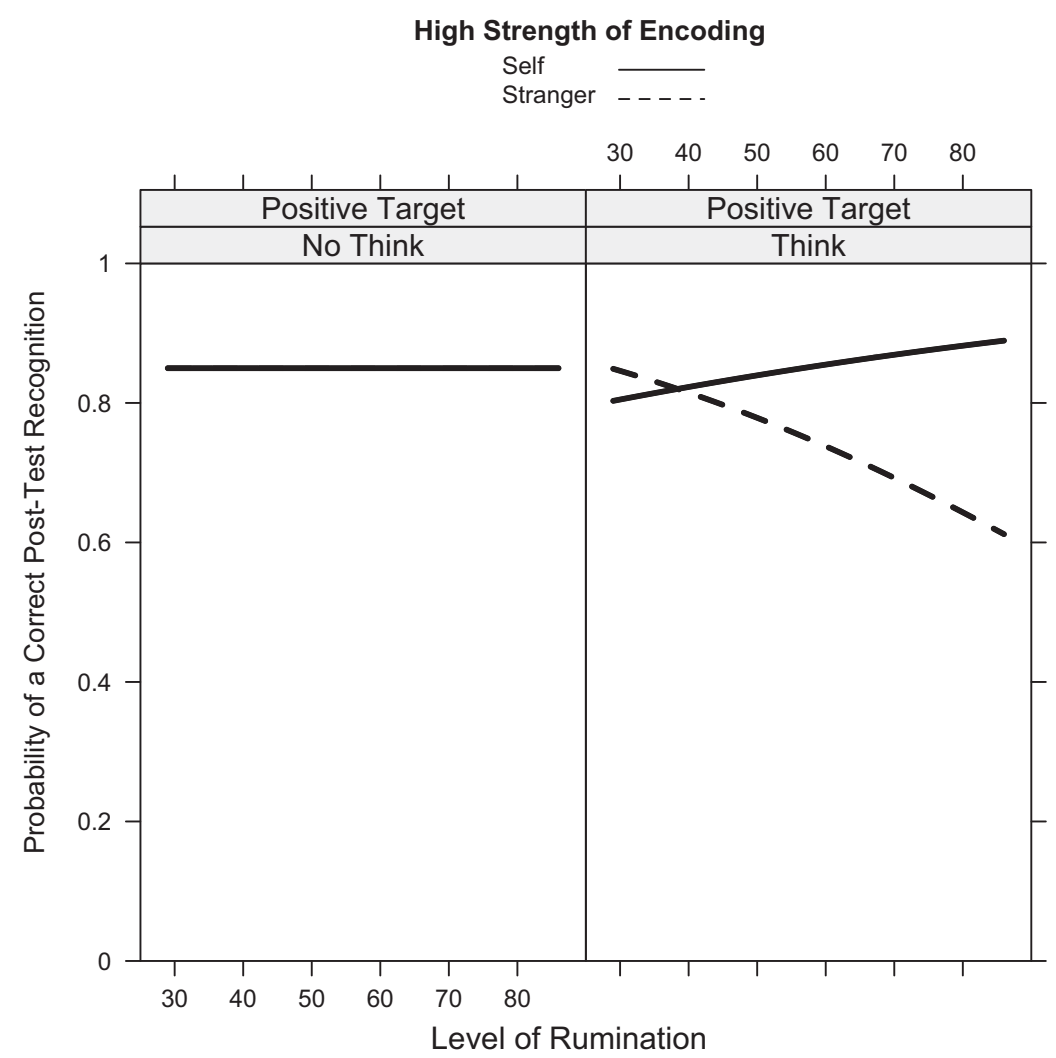

Fig. 5. Post-test accuracy for correct pre-test responses, positive targets. Probabilities of correct recognition as a function of level of rumination, referent, and think, for positively valenced targets.

For each participant, the proportions of correct post-test responses for self-referenced and other-referenced associations were also compared, Kendall $\tau_{b}=0.183(95 \% \mathrm{CI}$ : $-0.07,0.43)$. In the group of participants who scored below the 25th percentile on the CES-D scale, 4 participants showed the SRE, 4 showed the opposite effects, with 2 ties; in the group of participants who scored between the 25th percentile and 75th percentile, 9 showed the SRE, 16 showed the opposite effect, with 7 ties; in the group of participants who scored above the 75th percentile, 8 participants showed the SRE and 2 showed the opposite effect, with 1 tie.

Correct pre-test responses. For negative target pictures, the CES-D scores were not a significant predictor of post-test accuracy and they did not interact with think or referent, $\chi_{4}^{2}=1.12, p=.89$. The same result was also found for positive target pictures, $\chi_{4}^{2}=6.77, p=.15$.

\subsubsection{Overall effect of cognitive control on the post-test}

The overall effect of the think/no-think phase was tested with a GEE model in which the recognition accuracy in each trial of the post-test was the dependent variable, think (whether the cue image was used in a "think" or "no think" trial) was the predictor, and the pre-test score (correct or incorrect response) was used a covariate (e.g., Klar \& Darlington, 2004). In "think" trials, the mean proportion of correct responses on the pre-test was .76 compared to .74 on the post-test. In "no-think" trials, the proportions were .77 and .75 , respectively. The effect of the pre-test score was statistically significant: $\chi_{1}^{2}=276.48$, $p=.001$. Neither the variable think nor the interaction between think and the pre-test score were statistically significant, $\chi_{2}^{2}=2.1, p=.35$.

\subsubsection{Retrospective confidence judgments}

The binary RCJ judgments were analyzed with two GEE models with the vulnerability scores VF and referent as predictors, separately for positive and negative cues (Fig. 7). The main effect of VF was statistically significant (negatively valenced cues: $\chi_{1}^{2}=5.48, p=.019$; positively valenced cues: $\left.\chi_{1}^{2}=8.37, p=.004\right)$. The probability of a successful RCJ was higher when the cue portrayed the participant rather than a stranger (negatively valenced cues: $\chi_{1}^{2}=14.82, p=.001$; positively valenced cues: $\chi_{1}^{2}=26.37, p=.001$ ). The $\mathrm{VF} \times$ referent interaction was not statistically significant (negatively valenced cues: $\chi_{1}^{2}=0.58, p=.447$; positively valenced cues: $\chi_{1}^{2}=0.58, p=.447$ ). 


\section{Low Strength of Encoding}

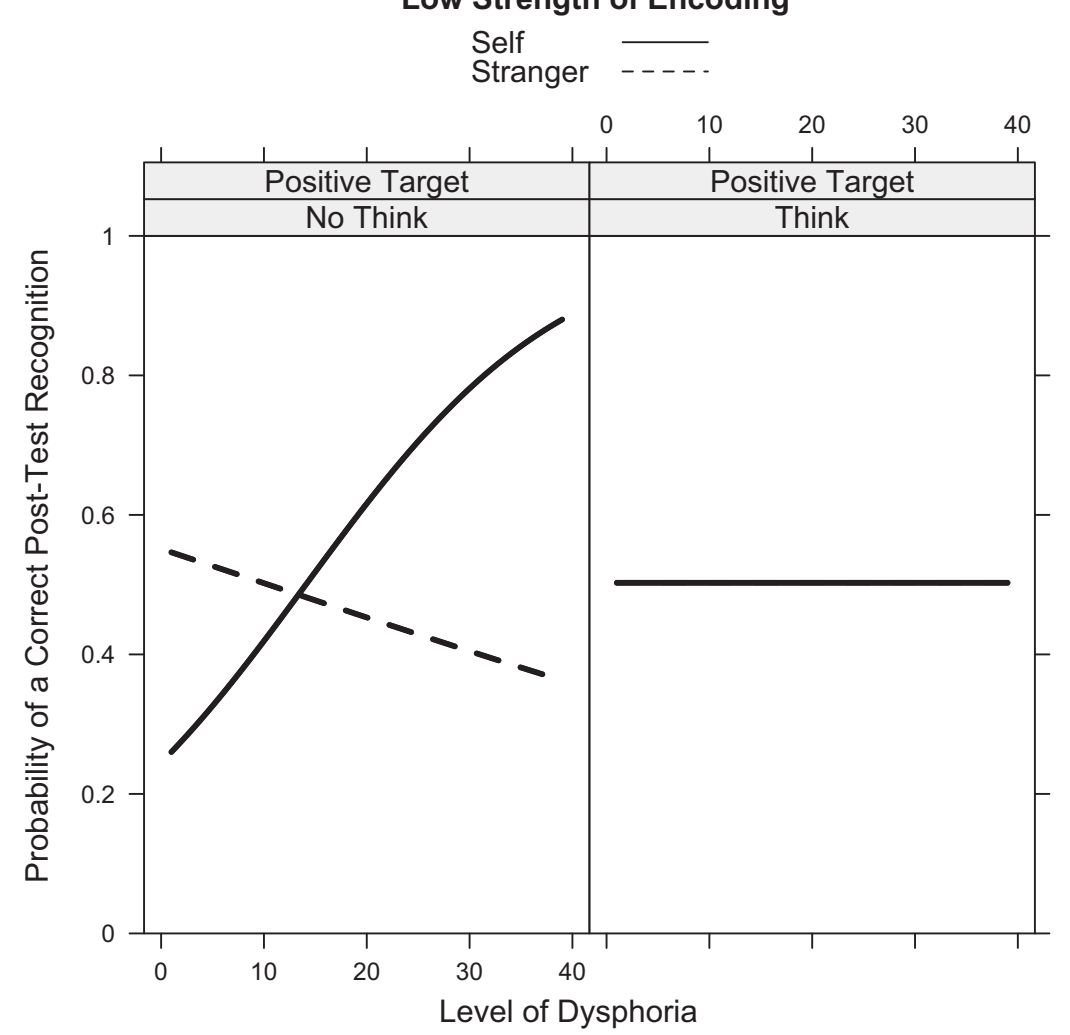

Fig. 6. Post-test accuracy for incorrect pre-test responses, positive targets. Probabilities of correct recognition as a function of level of dysphoria, referent, and think, for positively valenced targets.

\subsubsection{Compliance with the suppression instructions}

The probability of a successful compliance judgment was $2 \%$ higher when the cue portrayed a stranger rather than the participant (negatively valenced cues: $\chi_{4}^{2}=4.72, p=.030$; positively valenced cues: $\chi_{4}^{2}=5.20, p=.023$ ), indicating a greater difficulty to comply with the suppression instructions for self-referenced compared to other-referenced memories.

\subsubsection{Cognitive reflection test and negative cognitive style}

Fifty-five participants who had participated in Experiment 1 completed the CRT after the post-test. A GEE model analyzed the correct/incorrect responses to each problem as a function of $\mathrm{VF}$, controlling for gender and $\log 10$ (decision time). The effect of VF was statistically significant: $\exp (\beta)=11.7, \chi_{1}^{2}=6.29, p=.012,95 \% \mathrm{CI}=(1.71,80.41)$ : The predicted probabilities of a correct response ranged from .11 (lowest VF score) to .55 (highest VF scores).

\subsection{Discussion}

On the pre-test, an SRE was found for positive but not for negative cue-target associations. After the think/no-think phase, the "positivity bias" of the SRE was confirmed for those cue-target associations that had been responded to correctly on the pre-test. These results confirm the special status of positive self-referent information in memory (e.g., D'Argembeau et al., 2005).

However, there were large individual differences in the effects of mnemonic control over self-referenced information and other-referenced information. After a negative mood induction (which is postulated to activate latent negative schemas about the self and to bias information processing), participants high in negative cognitive style manifested a "maladaptive" SRE as a consequence of their attempts to suppress memory retrieval for negative self-referenced information (Fig. 3). This result was found for target-cue associations characterized by a low strength of encoding (i.e., for target-cue associations that had been responded to incorrectly on the pre-test), thus suggesting that dysfunctional control over memory is more likely in the case of weaker memories. Instead, when the strength of encoding was high (i.e., for target-cue associations that had been responded to correctly on the pre-test), an "adaptive" SRE was found for positively valenced information (Fig. 4). As in the pre-test, such "adaptive" SRE was not modulated by individual differences in negative cognitive style.

On the post-test, high brooding participants showed an SRE for positive cue-target associations used in "think" trials and having a high strength of encoding (Fig. 5). Being rumination a mode of self-focus, this might be due to the fact that high 


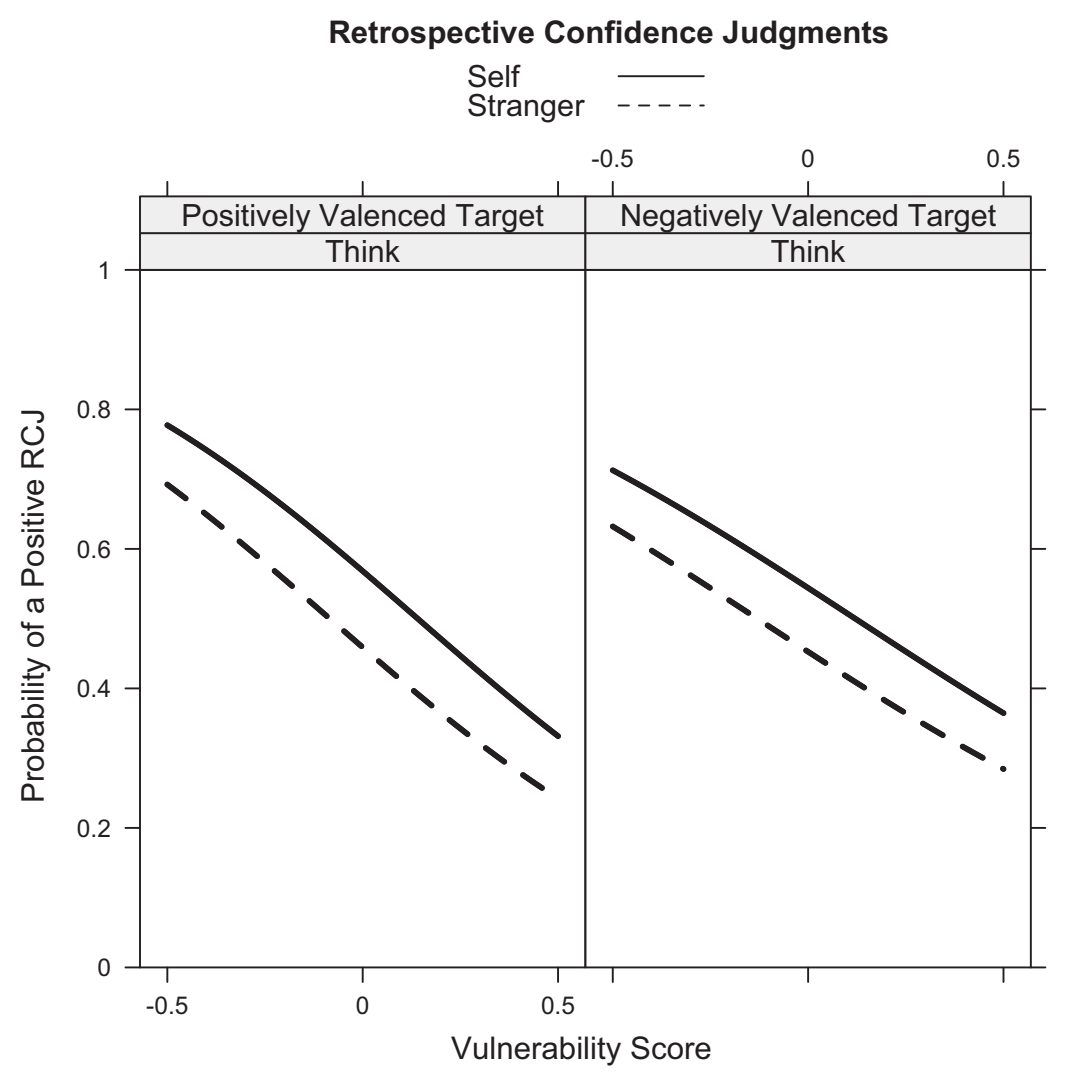

Fig. 7. Retrospective Confidence Jugdments. Probabilities of a successful RCJ response as a function of vulnerability score, think, valence, and referent.

brooding participants are less likely to retrieve positive other-referenced associations than positive self-referenced associations (see also Dieler et al., 2013).

On the post-test, participants experiencing high levels of dysphoria showed an SRE for positive cue-target associations used in "no-think" trials and having a low strength of encoding (Fig. 6). Consistent with Hertel and Gerstle (2003), therefore, dysphoric participants showed an ironic enhancement of memory for self-related positive information, when trying to suppress such information.

Participants high in negative cognitive style demonstrated to be less confident in their correct recall of target items, compared to participants low in negative cognitive style (Fig. 7). Because this reduced confidence in recollection ability did not reflect an actual deficit in performance, ${ }^{6}$ these results suggest that a maladaptive SRE is associated not only with high levels of negative cognitive style, but also with a dysfunctional metamemory. Interestingly, however, participants high in negative cognitive style performed better on the CRT then participants low in negative cognitive style. This suggests that a "maladaptive" SRE cannot be attributed to the decision-making style that is typical of those individuals who fail on this test (i.e., intuitive responding, parallel processing, automaticity, effortlessness, lack of insight into the decision process, and emotional influence).

Concerning the overall effectiveness of the think/no-think procedure, the present results provide no evidence for an impairment of recognition memory in "no-think" over "think" target-cue associations. This could be considered surprising, given that the effectiveness of the think/no-think procedure has been repeatedly demonstrated, also for cued-recognition performance (Hart \& Schooler, 2012; Nowicka, Marchewka, Jednoróg, Tacikowski, \& Brechmann, 2011; Tomlinson et al., 2009). However, there are a number of important methodological differences between the present study and those previous studies, the most important difference being that, in the present study, the think/no-think phase comprised only a small number of repetitions. The effectiveness of memory suppression is limited with a small number of think/no-think trials and increases with the number of repetitions (Depue, Banich, \& Curran, 2006). Here, a small number of think/no-think trials was chosen because it provides the best conditions to observe individual differences in the effects of cognitive control over memory (e.g., Joormann et al., 2005).

\footnotetext{
${ }^{6}$ Post-test accuracy as a function of individual differences in negative cognitive style was examined by means of a GEE model in which the post-test accuracy (correct or incorrect response) was the dependent variable, VF was the predictor, and the pre-test scores were used a covariate. The results of this analysis indicate that individuals high in negative cognitive style showed no overall impairment in post-test recognition accuracy: VF did not significantly affect posttest accuracy, $\chi_{1}^{2}=0.46, p=.50$, and it did not interact with the pre-test scores, $\chi_{1}^{2}=0.04, p=.84$.
} 
In summary, an "adaptive" SRE was found on the pre-test and, on the post-test, for those target-cue associations that had been used in "think" trials, when the strength of encoding was high. This "adaptive" SRE was not modulated by individual differences in negative cognitive style, rumination, or dysphoria. Conversely, a "maladaptive" SRE was found on the posttest, but only in cognitively vulnerable individuals. For these participants, a "maladaptive" SRE emerged as an ironic rebound effect from the specific attempts to suppress negative self-referenced associations, when the strength of encoding was low. This maladaptive SRE was associated to certain personality traits (negative cognitive style, but not rumination) and it was unrelated to negative affect (dysphoria).

\section{General discussion}

The main findings of the present study are the following.

1. An SRE was found in the cued recognition judgments of the pre-test, but only for positively valenced targets. This "adaptive" SRE was not modulated by individual differences in negative cognitive style, dysphoria, or rumination.

2. After their attempts at memory suppression, individuals high in negative cognitive style, who experienced a negative mood state that facilitate access to dysfunctional information processing, tended to remember the to-be-forgotten negative self-referenced targets better than prior to the think/no-think phase and better than negative other-referenced targets. For individuals high in negative cognitive style, therefore, the attempts at memory suppression of negative material produced a "maladaptive" SRE.

The novel aspect of the present findings is that cognitive control after encoding is an additional mechanism that may contribute to the memory advantage for self-related information, in addition to the strength of encoding (Klein, 2012; Klein, Loftus, \& Burton, 1989; Symons \& Johnson, 1997). However, the present results also show that volitional control, by interacting with a negative cognitive style, can transform the SRE into a "maladaptive" memory bias.

It should also be noted that participants who manifested a "maladaptive" SRE after the think/no-think phase showed no malfunctions of executive control for the processing of information unrelated to the self. This is shown by the results of the CRT. Moreover, in an additional experiment (not reported here), the participants also completed a facial-emotional variant of the Stroop task, with facial stimuli unrelated to the self. The results of this experiment show that performance in the Stroop task was not modulated by individual differences in negative cognitive style, rumination, or dysphoria.

One of the most surprising aspects of the present results is that participants high in negative cognitive style showed an ironic enhancement of memory when trying to suppress negative self-referenced information, and so did dysphoric participants for positive self-referenced information. These results are reminiscent of those obtained with the "white bear" paradigm (Wegner, 1994; Wenzlaff \& Wegner, 2000). In that paradigm, participants are asked not to think about a target thought (e.g., white bear) and the frequency of the forbidden thought is measured by a keypress whenever the thought comes to mind. The general finding produced by the "white bear" paradigm is that participants are more likely to think about the forbidden thought when instructed not to do so than when such instructions are not provided. Wegner (1994) explained this ironic memory enhancement in terms of a combination of operating and monitoring processes: The test that is performed to determine whether the behavioral goal is met ("avoid thinking about a white bear") can only be performed by bringing the forbidden thought into consciousness. Consistently with this hypothesis, Anderson and Huddleston (2011) have attributed this ironic memory enhancement to the key methodological difference between the "white bear" paradigm and the think/ no-think paradigm: Differently from the "white bear" paradigm, in the think/no-think paradigm the forbidden thought is never explicitly mentioned in the attempts of suppression. In the present adaptation of the think/no-think procedure, participants were required to provide a retrospective confidence judgment after each "think" trial and a judgment of compliance with the instructions after each "no-think" trial. Such continuous monitoring of performance (absent in the standard version of the think/no-think paradigm) may thus have activated an ironic control process of the sort of that hypothesized by Wegner (1994).

A recent study on the individual differences in the effects of the think/no-think paradigm that is closely related to the present work is the study of Dieler et al. (2013). In the "no-think" condition, Dieler et al. found that high brooding participants and high anxious participants showed above than baseline recall for negative cue-target associations. This finding is consistent with the present results in showing that dysfunctional personality traits can modulate the think/no-think effects and can produce an ironic enhancement of memory.

A few limitations of this study along with questions for future research should be noted. (1) A cued recognition task may tap into a different level of processing than cued recall (e.g., Hintzman, 2011). Therefore, it remains an open question whether the present results can be replicated by measuring self-referential memory by cued recall. (2) In the present study, all participants were subjected to a sad mood induction in order to prime maladaptive information processing in cognitively vulnerable individuals (Disner et al., 2011). It would be interesting to determine whether a "maladaptive" SRE can also be found in the absence of a negative mood induction. (3) Future research should extend the present results to clinical populations where dysfunctional cognitive control over memory is expected to produce a stronger "maladaptive" SRE.

A final consideration concerns the fact that the notion of self encompasses multiple dimensions and the self-referential processes investigated in this study may not be of the same nature as the processes assessed in previous studies that 
investigated the SRE for valenced information (e.g., Klein, 2012; Turk, Cunningham, \& Macrae, 2008). An important difference is that, in most previous studies, participants evaluated the self-descriptiveness of emotional traits and, therefore, emotional information was directly relevant to the self (i.e., it described personal characteristics). On the other hand, the paradigm used here involved associating pictures of the self with emotional pictures from the IAPS. Such pictures are not self-descriptive and there is no link between the emotional stimuli and the self, apart the episodic memory that was generated in the learning phase of the experiment. While previous studies used emotional stimuli that directly targeted one's self-concept, the emotional stimuli used in this study do not carry implications for the self-concept. Therefore, the memory mechanisms could be different in the two cases (e.g., by definition, self-enhancement can occur only occur when the processed information has implications for one's self-view). ${ }^{7}$

In conclusion, the present study shows that cognitive control after the encoding stage impacts the SRE in different manners, depending on individual differences in personality traits and affective states. In particular, repeated attempts to suppress memories of negatively valenced material result, in individuals high in negative cognitive style, in a better recognition accuracy for self-referenced information. In cognitively vulnerable individuals, therefore, dysfunctional cognitive control over memory can generate a "maladaptive" SRE.

\section{References}

Alloy, L. B., Abramson, L. Y., Hogan, M. E., Whitehouse, W. G., Rose, D. T., Robinson, M. S., et al (2000). The Temple-Wisconsin Cognitive Vulnerability to Depression (CVD) project: Lifetime history of Axis I psychopathology in individuals at high and low cognitive risk for depression. Journal of Abnormal Psychology, 109, 403-418.

Alloy, L. B., Abramson, L. Y., Keyser, J., Gerstein, R. K., \& Sylvia, L. G. (2008). Negative cognitive style. In K. S. Dobson \& D. J. A. Dozois (Eds.), Risk factors in depression (pp. 237-262). San Diego, CA: Elsevier Academic Press.

Anderson, M. C., \& Huddleston, E. (2011). Towards a cognitive and neurobiological model of motivated forgetting. In R. F. Belli (Ed.), True and false recovered memories: Toward a reconciliation. Nebraska symposium on motivation (Vol. 58, pp. 53-120). New York: Springer.

Anderson, M. C., \& Green, C. (2001). Suppressing unwanted memories by executive control. Nature, 410(6826), 366-369.

Aron, A. R. (2008). Progress in executive-function research: From tasks to functions to regions to networks. Current Directions in Psychological Science, 17, $124-129$.

Beck, A. T. (1967). Depression: Clinical, experimental, and theoretical aspects. New York: Harper \& Row.

Brainard, D. H. (1997). The psychophysics toolbox. Spatial Vision, 10, 437-442.

Caudek, C., \& Monni, A. (2013). Do you remember your sad face? The roles of negative cognitive style and sad mood. Memory, $21,891-903$.

Ceccarini, F., \& Caudek, C. (2013). Anger superiority effect: The importance of dynamic emotional facial expressions. Visual Cognition, 21, 498-540.

Clark, D. A., \& Beck, A. T. (2010). Cognitive theory and therapy of anxiety and depression: Convergence with neurobiological findings. Trends in cognitive sciences, $14,418-424$.

Conway, M. A. (2005). Memory and the self. Journal of Memory \& Language, 53, 594-628.

Conway, M. A., Singer, J. A., \& Tagini, A. (2004). The self and autobiographical memory: Correspondence and coherence. Social Cognition, 22, 491-529.

Cunningham, S. J., Turk, D. J., Macdonald, L. M., \& Macrae, C. N. (2008). Yours or mine? Ownership and memory. Consciousness and Cognition, 17, 312-318.

D'Argembeau, A. D., Comblain, C., \& Van der Linden, M. (2005). Affective valence and the self-reference effect: Influence of retrieval conditions. British Journal of Psychology, 96, 457-466.

Depue, B. E., Banich, M. T., \& Curran, T. (2006). Suppression of emotional and nonemotional content of memory: Efforts of repetition on cognitive control. Psychological Science, 17, 441-447.

Dieler, A. C., Herrmann, M. J., \& Fallgatter, A. J. (2013). Voluntary suppression of thoughts is influenced by anxious and ruminative tendencies in healthy volunteers. Memory, 1-10 (ahead-of-print).

Di Maria, F., \& Di Nuovo, S. (1991). Ideazioni disfunzionali e disagiopsichico, una ricerca con la Dysfunctional Attitude Scale di Beck e Weissman. Archivio di Psicologia, Neurologia e Psichiatria, 52, 233-249.

Disner, S. G., Beevers, C. G., Haigh, E. A., \& Beck, A. T. (2011). Neural mechanisms of the cognitive model of depression. Nature Reviews Neuroscience, 12, $467-477$.

Fava, G. A. (1982). Versione italiana del CES-D per la valutazione degli stati depressivi. Organizzazioni Speciali. Firenze.

Frederick, S. (2005). Cognitive reflection and decision making. The Journal of Economic Perspectives, 19, 25-42.

Glisky, E. L., \& Marquine, M. J. (2009). Semantic and self-referential processing of positive and negative trait adjectives in older adults. Memory, $17,144-157$.

Gutchess, A. H., Kensinger, E. A., Yoon, C., \& Schacter, D. L. (2007). Ageing and the self-reference effect in memory. Memory, $15,822-837$.

Hart, R. E., \& Schooler, J. W. (2012). Suppression of novel stimuli: Changes in accessibility of suppressed nonverbalizable shapes. Consciousness and Cognition, 21, 1541-1546.

Hertel, P. T., \& Calcaterra, G. (2005). Intentional forgetting benefits from thought substitution. Psychonomic Bulletin E’ Review, $12,484-489$.

Hertel, P. T., \& Gerstle, M. (2003). Depressive deficits in forgetting. Psychological Science, 14, 573-578.

Hewig, J., Hagemann, D., Seifert, J., Gollwitzer, M., Naumann, E., \& Bartussek, D. (2005). A revised film set for the induction of basic emotions. Cognition and Emotion, 19, 1095-1109.

Hintzman, D. L. (2011). Research strategy in the study of memory: Fads, fallacies, and the search for the coordinates of truth. Perspectives on Psychological Science, 6, 253-271.

Jallais, C., \& Gilet, A. L. (2010). Inducing changes in arousal and valence: Comparison of two mood induction procedures. Behavior Research Methods, 42, $318-325$.

Joormann, J., Hertel, P. T., Brozovich, F., \& Gotlib, I. H. (2005). Remembering the good, forgetting the bad: Intentional forgetting of emotional material in depression. Journal of Abnormal Psychology, 114, 640-648.

Joormann, J., Hertel, P. T., LeMoult, J., \& Gotlib, I. H. (2009). Training forgetting of negative material in depression. Journal of Abnormal Psychology, 118(1), 34-43.

Kanai, R., \& Rees, G. (2011). The structural basis of inter-individual differences in human behaviour and cognition. Nature Reviews Neuroscience, 12, $231-242$. Klar, N., \& Darlington, G. (2004). Methods for modelling change in cluster randomization trials. Statistics in Medicine, $23,2341-2357$.

Klein, S. B. (2012). Self, memory, and the self-reference effect an examination of conceptual and methodological issues. Personality and Social Psychology Review, 16, 283-300.

Klein, S. B., \& Loftus, J. (1988). The nature of self-referent encoding: The contributions of elaborative and organizational processes. Journal of Personality and Social Psychology, 55, 5-11.

\footnotetext{
7 The author thanks an anonymous reviewer for pointing this out.
} 
Klein, S. B., \& Kihlstrom, J. F. (1986). Elaboration, organization, and the self-reference effect in memory. Journal of Experimental Psychology: General, 115, 26-38.

Klein, S. B., Loftus, J., \& Burton, H. A. (1989). Two self-reference effects: The importance of distinguishing between self-descriptiveness judgments and autobiographical retrieval in self-referent encoding. Journal of Personality and Social Psychology, 56, 853-865.

Kuiper, N. A., \& Derry, P. A. (1982). Depressed and nondepressed content self-reference in mild depressives. Journal of Personality, 50, 67-80.

Lang, P. J., Bradley, M. M. \& Cuthbert, B. N. (2005). International affective picture system (IAPS): Affective ratings of pictures and instruction manual. Technical Report A-6. Gainesville, FL: University of Florida.

Leary, M. R. (2007). Motivational and emotional aspects of the self. Annual Review of Psychology, 58, 317-344.

Levy, B. J., \& Anderson, M. C. (2008). Individual differences in the suppression of unwanted memories: The executive deficit hypothesis. Acta psychologica, 127, 623-635.

Lovell, D., \& Zeffirelli, F. (1979). The champ [Motion picture]. USA: MGM/Pathe Home Video.

McCormack, H. M., Horne, D. J., \& Sheather, S. (1988). Clinical applications of visual analogue scales: A critical review. Psychological Medicine, 18, $1007-1019$.

Meins, E., McCarthy-Jones, S., Fernyhough, C., Lewis, G., Bentall, R. P., \& Alloy, L. B. (2012). Assessing negative cognitive style: Development and validation of a short-form version of the cognitive style questionnaire. Personality and Individual Differences, 52, 581-585.

Nolen-Hoeksema, S., \& Morrow, J. (1993). Effects of rumination and distraction on naturally occurring depressed mood. Cognition E Emotion, 7, 561-570.

Noreen, S., \& MacLeod, M. D. (2013). It's all in the detail: Intentional forgetting of autobiographical memories using the autobiographical think/no-think task. Journal of Experimental Psychology: Learning, Memory, and Cognition, 39, 375-393.

Nowicka, A., Marchewka, A., Jednoróg, K., Tacikowski, P., \& Brechmann, A. (2011). Forgetting of emotional information is hard: an fMRI study of directed forgetting. Cerebral Cortex, 21, 539-549.

Olino, T. M., Yu, L., Klein, D. N., Rohde, P., Seeley, J. R., Pilkonis, P. A., et al (2012). Measuring depression using item response theory: An examination of three measures of depressive symptomatology. International Journal of Methods in Psychiatric Research, 21, 76-85.

Palmieri, R., Gapsarre, A., \& Lanciano, T. (2007). Una misura disposizionale della Ruminazione depressiva: la RRS di Nolen-Hoeksema e Morrow. Psychofenia: Ricerca ed Analisi Psicologica, 17, 15-33.

Pelli, D. G. (1997). The VideoToolbox software for visual psychophysics. Spatial Vision, 10, 437-442.

Raaijmakers, J. G., \& Jakab, E. (2012). Rethinking inhibition theory: On the problematic status of the inhibition theory for forgetting. Journal of Memory and Language, 68, 98-122.

Radloff, L. S. (1991a). The CES-D Scale: A self-report depression scale for research in the general population. Applied Psychological Measurement, 1, 385-401.

Radloff, L. S. (1991b). The use of the center for epidemiologic studies depression scale in adolescents and young adults. Journal of Youth Adolescence, 20, $149-166$.

Robinson, O. J., Grillon, C. \& Sahakian, B. J. (2012). The mood induction task: A standardized, computerized laboratory procedure for altering mood state in humans. Protocol Exchange. doi:http://dx.doi.org/10.1038/protex.2012.007.

Rogers, T. B., Kuiper, N. A., \& Kirker, W. S. (1977). Self-reference and the encoding of personal information. Journal of Personality and Social Psychology, 35, $677-688$.

Safford, S. M., Alloy, L. B., Abramson, L. Y., \& Crossfield, A. G. (2007). Negative cognitive style as a predictor of negative life events in depression-prone individuals: A test of the stress-generation hypothesis. Journal of Affective Disorders, 99, 147-154.

Scherrer, M. C., \& Dobson, K. S. (2009). Predicting responsiveness to a depressive mood induction procedure. Journal of Clinical Psychology, 65, 20-35.

Sedikides, C., \& Green, J. D. (2000). On the self-protective nature of inconsistency-negativity management: Using the person memory paradigm to examine self-referent memory. Journal of Personality and Social Psychology, 79, 906-922.

Sedikides, C., \& Green, J. D. (2004). What I don't recall can’t hurt me: Information negativity versus information inconsistency as determinants of memorial self-defense. Social Cognition, 22, 4-29.

Segal, Z. V., \& Ingram, R. E. (1994). Mood priming and construct activation in tests of cognitive vulnerability to unipolar depression. Clinical Psychology Review, 14, 663-695.

Sica, C., Caudek, C., Rocco Chiri, L., Ghisi, M., \& Marchetti, I. (2012). Not just right experiences predict obsessive-compulsive symptoms in non-clinical Italian individuals: A one-year longitudinal study. Journal of Obsessive-Compulsive and Related Disorders, 1, $159-167$.

Symons, C. S., \& Johnson, B. T. (1997). The self-reference effect in memory: A meta-analysis. Psychological Bulletin, 121, $371-394$.

Tomlinson, T. D., Huber, D. E., Rieth, C. A., \& Davelaar, E. J. (2009). An interference account of cue-independent forgetting in the no-think paradigm. Proceedings of the National Academy of Sciences, 106, 15588-15593.

Turk, D. J., Cunningham, S. J., \& Macrae, C. N. (2008). Self-memory biases in explicit and incidental encoding of trait adjectives. Consciousness and Cognition, 17, 1040-1045.

Velten, E. (1968). A laboratory task for induction of mood states. Behavioural Research and Therapy, 6, 473-482.

Walker, W. R., \& Skowronski, J. J. (2009). The fading affect bias: But what the hell is it for? Applied Cognitive Psychology, $23,1122-1136$.

Watson, L. A., Dritschel, B., Obonsawin, M. C., \& Jentzsch, I. (2007). Seeing yourself in a positive light: Brain correlates of the self-positivity bias. Brain Research, 1152, 106-110.

Wegner, D. M. (1994). Ironic processes of mental control. Psychological Review, 101, 34-52.

Weissman, A. N. \& Beck, A. T. (1978). Development and validation of the dysfunctional attitude scale: A preliminary investigation. In Paper presented at the annual convention of the American Educational Research Association. Toronto, ON.

Wenzlaff, R. M. \& Wegner, D. M. (2000). Thought suppression. In S.T. Fiske (Ed.), Annual review of psychology (Vol. 51, pp. 51-91). Palo Alto, CA: Annual Reviews.

Wilson, A., \& Ross, M. (2003). The identity function of autobiographical memory: Time is on our side. Memory, 11, 137-149. 